\title{
Logistics Problems and Development Strategy under Cross-Border E-commerce Environment
}

\author{
Qiang $\mathrm{Ma}^{1, \mathrm{a}}$ \\ ${ }^{1}$ Business School, Xi'an International University, Xi'an, Shaanxi, 710077 \\ ${ }^{a}$ email
}

Keywords: Cross-Border E-Commerce, Logistics, Development Strategy

\begin{abstract}
With optimal adjustment of the process of globalization and accelerate China's economic policy, cross-border e-commerce transactions are springing up rapidly. Become a branch of import and export trade torrent integral, innovative and vitality. However, the problem is the logistics market after vigorous Restrictive factors. How to break this bottleneck? By analyzing the environment under the cross-border E-commerce logistics problems and to explore the effective strategies for future development, put forward their own little thinking.
\end{abstract}

\section{Introduction}

In 2014, Alibaba's "Lynx International" swept, triggered a "buy overseas" market boom [1]. Because the E-commerce industry across the low barriers to entry, a small amount of the cost of investment, government support, extensive consumer groups, variety of goods. More and more cross-border business enterprise rise, well-known brands have settled. In 2016 and the beginning of plans to build a new wave of cross-border E-commerce comprehensive test area (2012 in some cities have been successful construction of the first pilot), equally warm response. Undeniably Chinese cross-border E-commerce has shown a booming trend, according to relevant statistics, import and export trade volume of cross-border E-commerce at the end of 2016 is expected to exceed 6.5 trillion yuan [2]. Inseparable from the supporting role of logistics in this lively behind, as a kind of different from the traditional stream of modern logistics, in all aspects of operational efficiency and operating techniques, operating conditions can not comply with the requirements of cross-border E-commerce, has a more a large room for improvement, so in the new era of increasingly fierce market competition environment, how to achieve stable and rapid development of cross-border E-commerce has become an urgent problem.

\section{The Concept of Cross-Border E-commerce and Related Common Logistics Business Model}

Cross-border E-commerce characteristics. Cross-border E-commerce, as the name implies, it refers to enterprises or individuals through e-commerce platform, the use of scientific and technical information and the means to carry out import and export trade-related business activities. For example, display of goods, to discuss cooperation, and other aspects of the payment transaction. Depending on the direction of the flow of goods, divided into cross-border electricity importers (mainly bonded stocking) and an outlet cross-border E-commerce (overseas direct mail). Formally, there are cross-border E-commerce B2B, B2C these two models, in addition to some cities introduced innovative $\mathrm{O} 2 \mathrm{O}$ mode, will experience offline and online purchase together, increase the user experience of consumption [3] . Therefore, the development of cross-border e-commerce so that consumers really have to go out will be able to enjoy the products and services from around the world the opportunity to make people's lives more convenient and colorful. Therefore, in order to successfully achieve the development goals, to meet the demand for more, break time, space, cost and other constraints, we need to strictly control every aspect of their supply chain.

The characteristics of the logistics business. Logistics is a crucial cross-border E-commerce content, related to the storage and transport of goods, at this stage of the cross-border E-commerce logistics model are the following. First, postal parcels mode. As the most widely used form of logistics global coverage, it has the incomparable superiority. Goods transport is the preferred 
logistics manufacturing production enterprises. It does this by way of personal mail postal packets, goods to any corners. Advantage is low cost, a wide and easy to operate. But the low level of information technology, logistics slow is obvious defects; second, international express delivery mode. Parcel delivery performed by the USP, DHL international courier companies. Intensive services, high speed, high efficiency, improve information systems. However, because so many expensive SMEs prohibitive. Third, the domestic express mode. As e-commerce carried out in full swing, many of our traditional logistics also try to carry out overseas logistics business. Such as SF in some Southeast Asian neighboring countries express delivery business gradually mature, however, compared with the international logistics, information accessibility is not high, it is difficult to achieve effective delivery. Overall, China's current cross-border e-commerce logistics as an emerging logistics industry is still lagging behind in the state, there are many problems to be solved and should be improved.

\section{Cross-border E-commerce Logistics Bottlenecks Currently Faced with Constraints}

Complex logistics program. Compared with the traditional ordinary logistics, the special nature of cross-border e-commerce, so the cross-border E-commerce logistics environment is more complex distribution chain span, to go through multiple levels of testing, the integration of a variety of network information, related to the sea transport links warehousing and distribution problems, so difficult, long cycle, with certain risks.

Higher logistics costs. Since the first delivery time is generally between two weeks and one month, the steps involved and many links, transaction costs and therefore increase. Secondly, the net purchase objects not directly observable, so there will be a variety of uncertainties, such as the quality of goods damaged items, items are missing, replacement procedures as a result of the trouble prone to problems or fixed return loss of consumers, this time, the cost of a single piece of folded produced commodities is relatively high. In addition, together with quality control of goods at Customs when prone to "confiscated", the loss due to the special situation caused also indirectly increase the cost of logistics [4] cross-border E-commerce.

The distribution of goods is limited. Logistics and transport due to the long period of time, resulting in delivery of goods cross-border e-commerce presence conditionality, especially in the modern living standards improve, the demand for fresh fruits and vegetables and seafood products continues to expand, but in cross-border transportation prone to the problem of deterioration the one hand, people can not enjoy the quality and quantity of fresh services; on the other hand the outstanding domestic fresh produce can not be delivered to the hands of consumers, not help to improve the economic efficiency of agricultural products. Therefore, how to use high-end technology to improve the freshness of fresh products under the premise of cost control and optimize the transport chain is a tricky bottleneck.

Inadequate logistics and warehousing. With the increasing use of e-commerce to expand the range, there are obvious faults supply and demand warehouse resources. Especially in case of special promotional activities during the day, a sharp increase in the volume of orders caused by the seller to the enterprise a lot of pressure. Plus cross-border E-commerce logistics operations have complex characteristics, resulting in goods statistical problem of insufficient management. In addition, although the strong support of the national government departments under the cross-border E-commerce service environment has improved to a large extent, but there are still parts of poor infrastructure, outdated technology, the degree of information and weak flawed, warehouse construction area shortage also affects the storage play its function in logistics.

\section{Effective Strategies at Cross-Border E-Commerce Logistics Development Environment}

Logistics cost control is the business enterprise that need attention. How to ensure the quality and efficiency of logistics, is an urgent problem to be solved at the lowest possible cost. Due to the small number of the many cross-border trade, small, not suitable for large containers shipped by sea. So it can take full advantage of ocean storage channels to resolve. Overseas warehouse can and 
specialized companies to cooperate and to be traded during the region to establish their own sub-warehouse. According to market research and forecasting in advance of the results of the goods to the warehouse. The first delivery, and then sales. This model help to avoid the risk of goods transportation, customs clearance, commodity inspection and other links, shorten delivery cycles, improve transport efficiency [5]. After receiving the order directly to the warehouse of goods are for distribution overseas. Both to improve the credibility of the product, but also to expand the visibility, expand import and export business, reduce logistics costs, but also conducive to timely detection and inventory management, and will not produce the goods supplied to the pressure in the high season, in the event of special circumstances need to be returned it is possible to efficiently complete the processing work goods.

Although the use of overseas warehousing goods distribution model can solve the problem and reduce costs, the key feature of this model is based on play accurately predict market demand and sales to the premise. If the predicted results and the reality there is a big discrepancy or untrue situation will lead to poor sales of goods occurred, resulting in unnecessary waste of resources in the warehouse, but increased costs. Therefore, to increase the use of information processing technology, improve the overall capacity of the cross-border electronic business platform, for accurate data processing and prediction, and even the use of information technology to logistics whereabouts of dynamic regulation, reduce loss frequency goods. Improve the efficiency of logistics and transport.

Cross-border E-commerce logistics constraints detected by Customs, which led to a long period of transport, part of the complex, which makes the low efficiency of logistics and risk, especially for fresh ingredients, it is a big constraint obstacles. The product itself is perishable, difficult to store in advance, so we can improve the program for the more tedious aspects of clearance, to improve efficiency by reducing the clearance time or simplified procedures. For example, fresh fruit, can take the form of newspaper distribution set, which allows delivery logistics in batches to ensure freshness of supply, and then the data and documents provided to achieve unity declaration. So we should in the shortest possible time to preserve the value of the goods.

At the moment the cross-border transport of E-commerce logistics analysis, common transport channel is the air and sea. And concentrated in the southeast coastal areas, although transport capacity strong, fast, but susceptible to weather and other natural climate and environment, and greater cost. It can not effectively control the duration of transport. In order to effectively alleviate the pressure of these two modes of transport and logistics make up for deficiencies on both at the same time expand our foreign market, it should be to strengthen the railway construction in the western region. It may have more choices to make on cross-border logistics and transport of goods. In addition, the resources of the western region rich resources, through the "Silk Road railway" construction increased trade with Europe, the Middle East and other regions. It can enrich the level of cross-border logistics, seamless docking overseas markets, strengthen ties with various countries of the world. As in 2014, "thousands of miles across the" Central Europe's longest international rail freight trains, "meaning a new Europe," the official in Zhejiang Yiwu CDB; the Southern Xinjiang Railway Turpan-Korla build the second line, has covered Xinjiang, Gansu and other provinces for China's cross-border electricity the smooth operation of the logistics provides a good opportunity for development [6].

\section{Conclusion}

In conclusion, in the context of economic globalization, cross-border E-commerce logistics is a development of the situation and adapt to the times to produce innovative things. Born out of the traditional logistics model, but also in promoting the existing advantages on the basis adds many new features. Faced with the problems and bottlenecks facing difficulties, we have to take measures to fully resolve and improvement, in addition to several strategies proposed in this paper, but also has a strong focus on training business skills and the ability to respond flexibly to complex talent and the promotion of cross-border sustainable development of the E-commerce industry. 


\section{References}

[1] Zhao Sujuan, Peng Zhaoxia. Development Strategy of cross-border e-commerce environment China Post [J]. Education Forum, 2014 (29): 168-169.

[2] Wan Ying. status quo of cross-border e-commerce logistics, challenges and countermeasures [J]. China Logistics and Purchasing, 2014 (20): 68-69.

[3] Ke Jinglin, Jiang Weijun. electricity business environment Development Strategy Based on China's express delivery industry competitiveness Perspective Chinese express industry to enhance the image [J]. Logistics Technology, 2014 (3): 124-126.

[4] Yao Chao. Situation and Development Strategy of China's express delivery industry under the e-commerce environment [J]. Citation Version: Engineering and Technology, 2015 (14): 1-1.

[5] Du Linlin. Situation e-commerce environment of logistics management analysis and countermeasures [J]. reform and opening up, 2012 (8): 26-26.

[6] Fu Suozhi. Under the Chicago Innovation Strategies of e-commerce environment of logistics management [J]. management observation, 2015 (10): 77-78. 